\title{
A Bayesian Approach for Validation of Election Results
}

\author{
${ }^{*}$ R. K. Ogundeji and J. N. Onyeka-Ubaka \\ Department of Mathematics, University of Lagos, Nigeria \\ [Corresponding Author: E-mail: rogundeji@unilag.edu.ng, jonyeka-ubaka@unilag.edu.ng]
}

\section{ABSTRACT}

Election process and results in many countries have resulted in both political and economic instability of that country. Fair and credible election process and results must be evidence-based and statistical proven. This study employed a Bayesian procedure for the validation of election results. Based on Nigerian 2011 and 2015 presidential election results, Bayesian credible intervals were obtained to assess the credibility of Nigeria presidential election results. The study explores Bayesian methods using a Bayesian model called beta-binomial conjugate model to compute posterior probability of electoral votes cast and confirm if these votes are within Bayesian credible intervals. The results obtained showed that election outcomes for the two major political parties in Nigeria 2011 presidential election are not within Bayesian credible bounds while 2015 presidential election results are within computed Bayesian credible bounds. Also, in contrast to frequentist approach, applied Bayesian methodology exhibited smaller variance which is an indication that Bayesian approach is more efficient. Thus, for election to be fair, credible and acceptable by the electorates, Bayesian approach can be used to validate electoral process and results.

Keywords: Bayesian Methods, Bayesian Credible Intervals, Beta-Binomial Model, Empirical Bayes, Nigeria Presidential Elections.

\section{INTRODUCTION}

An election is a formal decision-making process by which a particular population chooses an individual to occupy a political office for the sole aim of public service. In the electioneering process, the candidate of a particular political party wins the election by securing the votes of majority of the population. Faced with controversies such as multiple registrations of voters by a single individual, illegal compilation of separate voters lists, irregularities between figures of registered voters and actual votes, falsification or outright inflation of election results, ballot box stuffing and snatching, mathematicians and statisticians have attempted to devise a suitable technique to analyze electoral processes following the conduct of elections. In a bid to combat the problems and challenges faced with the conduct of a free and fair election in Nigeria, election surveys are conducted to give insights into the events surrounding an election. Bayesian inference has been proven to be an appropriate method for handling similar issues.
Many authors have worked on election processes and results and have considered issues of election forecasting, electoral behaviour, pre-election survey among others. Examples of such authors include: Holbrook and DeSart (1999), Christensen and Florence (2008), Hillygus (2011), Lewis-Beck (2005), Rosenstone (1986), Mann (2005) and Stegmuller (2014). Others are, Brown and Chappell (1999) who focused on elections forecasting using history and polls; Rigdon, et al., (2009) who presented a Bayesian model to predict winners in the U.S. Senate and presidential elections in 2012 and 2014; Kenneth (2014) who focused on least informative priors to study the validity of the gubernatorial elections in Ghana; Iwok and Akpan (2016) who studied Nigerian 2015 presidential polls using beta prior.

Researchers have used frequenstist methods for statistical analysis until technological advances and introduction of certain algorithms such as Markov Chain Monte Carlo, gave way to increase computational power that enabled complex calculations to be done using Bayesian 


\section{Ogundeji and Onyeka-Ubaka: A Bayesian Approach for Validation of Election Results}

procedures (Gray et al., 2015). However, Bayesian statistics add the component of a prior distribution based on prior knowledge and/or expert opinions on the subject. Bayesian inference derives the posterior probability as a consequence of two antecedents, a prior probability and a likelihood function derived from a statistical model of the observed data (Lee, 2004).

Thus, this study explores Bayesian methods to ascertain the credibility of votes cast in 2011 and 2015 Nigeria presidential election. In particular, a Bayesian model called beta-binomial conjugate model was employed to compute posterior probability of electoral votes cast and confirm if these votes are within Bayesian credible intervals. The beta-binomial model is a conjugate model that assumes a binomial likelihood distribution and a beta prior distribution to produce a beta posterior distribution. The Bayesian approach adopted and applied empirical Bayes (EB) methodology to determine the prior probabilities for the study, which are needed to derive the posterior probabilities $\left(\mathrm{P}_{\mathrm{EB}}\right)$. This is achieved by combining information from several but similar sources. The primary interest in EB analysis is in the hyperparameters $(\eta)$ rather than the parameters from individual studies $(\theta)$ (Theobald and Wuttke, 2006). More importantly, EB can lead to more precise estimates than sampling theory (frequentist) approaches as it uses related supplementary data which frequentist inference ignores (Okafor
1999; Okafor et al., 2010; Ogundeji and Okafor, 2012). The remainder of the paper is organised as follows: empirical Bayes method adopted to estimate the parameters of the beta-binomial model is described. This is followed by the analysis of the reported election results, the estimates of the parameters of the beta-binomial model and Bayesian credible intervals estimates. The paper discusses the research outcome and relates it to similar articles with some concluding remarks.

\section{METHODOLOGY Empirical Bayes (EB) Process}

This study covers the 2011 and 2015 presidential elections in the South West region (i.e. South West geopolitical zone) in Nigeria. The six Southwestern states in Nigeria include Ekiti, Lagos, Ogun, Ondo, Osun and Oyo. To this effect, the official 2011 and 2015 presidential election results in the South-western states of Nigeria were employed as secondary data sourced from the constituted electoral umpire in Nigeria, the Independent National Electoral Commission (INEC)

(https://www.inecnigeria.org/elections/elec tionresults/, cited $23^{\text {rd }}$ Nov. 2016). The top-two political parties that participated in 2011 and 2015 presidential elections, considered in this study include: People Democratic Party (PDP) and Action Congress of Nigeria (ACN) for 2011 and All Progressive Congress (APC) and People Democratic Party (PDP) for 2015.

Using the EB process, we define the following:

$$
y_{i j}=\left\{\begin{array}{c}
1 \text { if an electorate vote for a particular party in a state } j \\
0 \quad \text { Otherwise } \\
\quad \text { Where } \mathrm{i}=1,2, \ldots, \mathrm{n}_{\mathrm{j}} \text {. and } \mathrm{j}=1,2, \ldots, 6 .
\end{array}\right.
$$

$y_{j}=\sum_{i=1}^{n_{j}} y_{i}$ is the total number of electorates in

favour of a political party in state $j$

$y=\sum_{i=1}^{n_{j}} \sum_{j=1}^{6} y_{i j}$ is the total number of electorates

in favour of a political party in six states. $n_{j}$ is the total number of electorates that voted in state j of South West zone $\mathrm{n}=\sum_{j=1}^{6} n_{j}$ is the total number of electorates that voted in the six states of South West zone. 


\section{Nigerian Journal of Basic and Applied Science (December, 2019), 27(2): 22-31}

$\mathrm{N}$ is the total number of registered voters or total number of eligible voters, some of which may not vote in the election.

For each state, we computed the sample proportions $\mathrm{P}_{. \mathrm{j}}$ as $P_{. j}=\frac{\sum_{i=1}^{n_{j}} \sum_{j=1}^{6} y_{i j}}{n_{j}}$

The Beta-Binomial Model

The EB model to be applied is a conjugate BetaBinomial model, where the binomial distribution represents the likelihood of the observed data while the beta distribution serves as the prior distribution of the binomial parameter. The posterior mean is

$$
\begin{gathered}
\tilde{P}_{. j}=\int P_{. j} f\left(P_{. j} \mid y_{. j}, \eta\right) d P_{. j} \cdot \quad(1) \\
f\left(P_{. j} \mid y_{. j}, \eta\right)=\frac{\left(\begin{array}{c}
n_{. j} \\
y_{. j}
\end{array}\right) P_{j}^{y_{j}}\left(1-P_{. j}\right)^{n_{. j}-y_{. j}} \frac{1}{B(r, s)} P_{\cdot j}^{r-1}\left(1-P_{. j}\right)^{s-1}}{\int P_{. j}^{y_{j}}\left(1-P_{. j}\right)^{n_{j}-y_{. j}} \frac{1}{B(r, s)} P_{. j}^{r-1}\left(1-P_{. j}\right)^{s-1} d P_{. j}}, \quad \eta=(r, s) .
\end{gathered}
$$

There is the need to estimate the hyperparameters $r$ and $s$ of the beta distribution in order to specify the appropriate conjugate prior and its distribution. This can be achieved through reparameterisation of $f\left(P_{. j} \mid \eta\right)$ and by using
Estimators of sample proportions: $\quad \hat{P}=\frac{\sum_{j} y_{. j}}{n}$ and $\quad \operatorname{Var}(\hat{P})=\frac{\hat{P}_{. j}\left(1-\hat{P}_{. j}\right)}{n_{j}}$.

A key component of this integral is $f\left(P_{. j} \mid y_{. j}, \eta\right)$, the posterior distribution of $P_{. j}$. Under the general Bayesian framework and using the beta conjugate prior plus the binomial likelihood, the posterior distribution of $P_{. j}$ is given in equation (2), (Adewara and Ogundeji, 2017):

$$
E\left(P_{. j}\right)=P_{o} \text { and } \operatorname{Var}\left(P_{. j}\right)=\frac{r s}{(r+s+1)(r+s)^{2}}=\frac{P_{o}\left(1-P_{o}\right)}{M+1} \text {. }
$$

These are known as prior mean and variance, respectively. Consequently,

$$
f\left(P_{. j} \mid y_{. j}, \alpha, \beta\right)=\frac{1}{B(\alpha, \beta)} P_{. j}^{\alpha-1}\left(1-P_{. j}\right)^{\beta-1}
$$

Where; $\hat{\alpha}=y_{. j}+m \hat{p}_{o}, \hat{\beta}=n_{. j}-y_{. j}+m\left(1-\hat{p}_{o}\right)$, and $\hat{P}_{o}=\frac{\sum_{j} y_{. j}}{\sum_{j} n_{j}}$

while $m$ is estimated as $\hat{\mathrm{M}}=\frac{\hat{P}_{o}\left(1-\hat{P}_{o}\right)-S_{P}^{2}}{S_{P}^{2}-\frac{\hat{P}_{o}\left(1-\hat{P}_{o}\right) \sum \frac{1}{n_{j k}}}{N}}, \quad$ for $S_{P}^{2}=\frac{N \sum n_{j}\left(\hat{P}_{. j}-\hat{P}_{o}\right)^{2}}{(N-1) \sum n_{j}}$.

With $m$ and $P_{o}$ estimated, then; 


\section{Ogundeji and Onyeka-Ubaka: A Bayesian Approach for Validation of Election Results}

$$
\begin{aligned}
& \tilde{P}_{E B}=E\left(P_{. j} / y_{. j}, \hat{P}_{o}, \hat{\mathrm{M}}\right)=\frac{\alpha}{\alpha+\beta}=\frac{y_{. j}+\hat{\mathrm{M}} \hat{P}_{o}}{n_{j}+\hat{\mathrm{M}}}=\left(\frac{\hat{\mathrm{M}}}{n_{j}+\hat{\mathrm{M}}}\right) P_{o}+\left(\frac{n_{j}}{n_{j}+\hat{\mathrm{M}}}\right) \frac{y_{. j}}{n_{j}} \\
& \text { where } \quad \operatorname{Var}\left(\tilde{p}_{E B}\right)=\frac{\alpha \beta}{(\alpha+\beta+1)(\alpha+\beta)^{2}} .
\end{aligned}
$$

Under conjugacy, the EB estimator of a proportion $\hat{P}_{. j}$ is a weighted mean of two estimators, the mean of the prior density $P_{o}$ and the sample proportion estimator $\hat{P}_{. j}$. Thus, $\tilde{P}_{E B}=\lambda P_{o}+(1-\lambda) \hat{P}_{. j}$

$\widetilde{P}_{E B}$ is the empirical Bayes Estimator with $\lambda$ as the shrinkage factor given as $\hat{\lambda}=\frac{\hat{M}}{n_{j}+\hat{M}} . \lambda$ is a function of the prior and sample estimator variances such that, if variance of sample estimator is large, the weight of $\hat{P}_{o}$ (i.e. $\lambda$ ) will be large and $\widetilde{P}_{E B}$ will shrink towards $\hat{P}_{o}$. The two parameters of the above model $\lambda$ and $\hat{P}_{o}$ are derived from the EB process (Okafor 1999: Carlin and Louis, 2000; Ogundeji and Okafor,
2010). Using the $\widetilde{P}_{E B}$, the expected votes for a state represented as $E(y)$ is computed for each state.

The Bayesian credible interval estimates are given as: $\widetilde{P}_{E B} \pm Z_{\alpha} \sqrt{\operatorname{Var}\left(\widetilde{P}_{E B}\right)}$ $Z_{a}$ is the interval coefficient at a level of significance. Thus, a 95\% Bayesian credible interval provides a range for a parameter such that the probability that the parameter lies in that range is $95 \%$. The Bayesian credible interval estimates in (7) compute the range of values within which the expected votes for each state will fall (Lee, 2004; Gray et al., 2015). It is an interval in the domain of posterior probabilities $\tilde{P}_{E B}$ bounded by lower credible limit $(\mathrm{LCL})$ and Upper Credible Limit (UCL). With these credible limits, corresponding Lower Credible Votes (LCV) and Upper Credible Votes (UCV) are computed.

$$
\begin{gathered}
E\left(\frac{y_{i j}}{\eta_{i j}}\right)=E\left[E\left(\frac{y_{i j}}{\eta_{i j}} \mid P_{i j}\right)\right]=E\left(P_{i j}\right)=P_{o} \\
\operatorname{Var}\left(\frac{y_{i j}}{\eta_{i j}}\right)=\operatorname{Var}\left[E\left(\frac{y_{i j}}{\eta_{i j}} \mid P_{i j}\right)\right]+E\left[\operatorname{Var}\left(\frac{y_{i j}}{\eta_{i j}} \mid P_{i j}\right)\right] \\
=\operatorname{Var}\left(\pi_{i j}\right)+E\left(\frac{P_{i j}\left(1-P_{i j}\right)}{\eta_{i j}}\right) \\
E\left(P_{i j}\left(1-P_{i j}\right)\right)=E\left(P_{i j}\right)-\operatorname{Var}\left(P_{i j}\right)-\left[E\left(P_{i j}\right)\right]^{2} \\
\operatorname{Var}\left(\frac{y_{i j}}{\eta_{i j}}\right)=\operatorname{Var}\left(P_{i j}\right)+\frac{1}{\eta_{i j}}\left\lfloor E\left(P_{i j}\right)\left(1-E\left(P_{i j}\right)\right)-\operatorname{Var}\left(P_{i j}\right)\right] \\
=P_{o}\left(1-P_{o}\right)+\frac{P_{o}\left(1-P_{o}\right)}{\eta_{i j}}-\frac{P_{o}\left(1-P_{o}\right)}{\eta_{i j}(M+1)} \\
\left.=\frac{P_{o}\left(1-P_{o}\right)}{\eta_{i j}}\left(1+\frac{\eta_{i j}-1}{M+1}\right)\right]
\end{gathered}
$$




$$
=\frac{1}{k} \sum \frac{\hat{P}_{o}\left(1-P_{o}\right)}{\eta_{i j}}\left(1+\frac{\eta_{i j}-1}{M+1}\right)
$$

Let $\operatorname{Var}\left(\frac{y_{i j}}{\eta_{i j}}\right)=S_{P_{i}}^{2}$; then working through the algebra $\hat{M}=\frac{\hat{P}_{o}\left(1-\hat{P}_{o}\right) N-S_{P_{i}}^{2}}{S_{P_{i}}^{2}-\frac{\hat{P}_{o}\left(1-\hat{P}_{o}\right)}{N} \sum \frac{1}{\eta_{i}}}$

\section{RESULTS}

From data: $\hat{P}_{o}=\frac{\sum y_{i j}}{\sum n_{i j}}$ and

Based on the reported votes cast (y) from the respective states of the south west zone in 2011 and 2015 presidential elections and the methodology adopted both the prior probabilities $\left(P_{0}\right)$ and posterior probabilities $\left(P_{E B}\right)$ for the expected votes $\mathrm{E}(\mathrm{y})$ were computed.

The Bayesian credible intervals were also computed for each state as lower credible limit (LCL) and Upper Credible Limit (UCL). Using the credible limits, corresponding Lower Credible Votes (LCV) and Upper Credible Votes (UCV) were computed. Further analysis of the credibility of votes cast is shown in the difference between reported votes and expected votes [y-E(y)]. The results of analysis are displayed in Tables 1 and 2.

The analysis of reported votes for the 2011 presidential election in favour of PDP in Table 1 shows a marked difference between reported votes and expected. Moreover, all reported votes cast in favour of PDP in the respective states are not within the computed Bayesian interval bounds (LCV and UCV). This is an indication of irregularities in the election process given the reported votes from each state. In addition, lack of credibility in the election process is noted in reported vote cast in favour of $\mathrm{ACN}$ from the respective states. Again, in Table 2 there is a marked difference between reported and expected votes and the votes from the respective states are not within the computed Bayesian interval bounds. These results are graphically represented in Figures 1 and 2.
$\widehat{\operatorname{Var}}\left(\frac{y_{i j}}{\eta_{i j}}\right)=S_{P_{i}}^{2}=N \frac{\sum n_{i}\left(P_{i}-\hat{P}_{o}\right)}{(N-1) \sum n_{i}}$

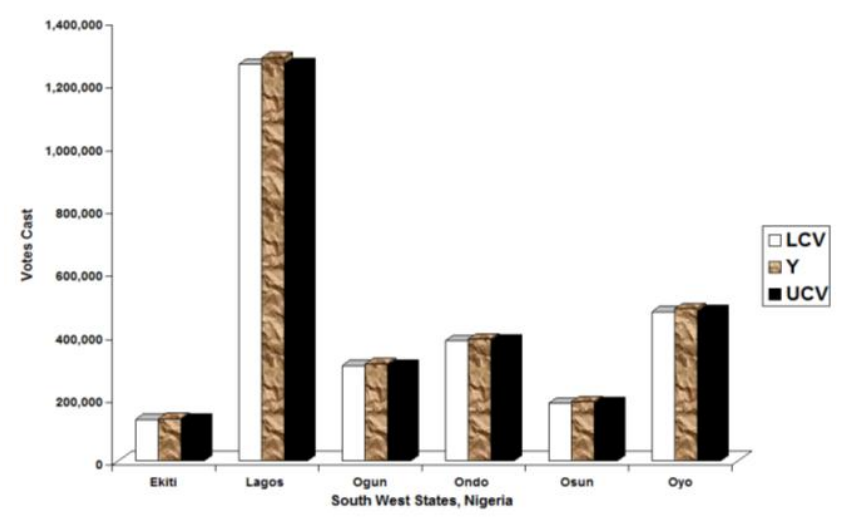

Figure 1: Electoral votes cast in favour of PDP in 2011 presidential election

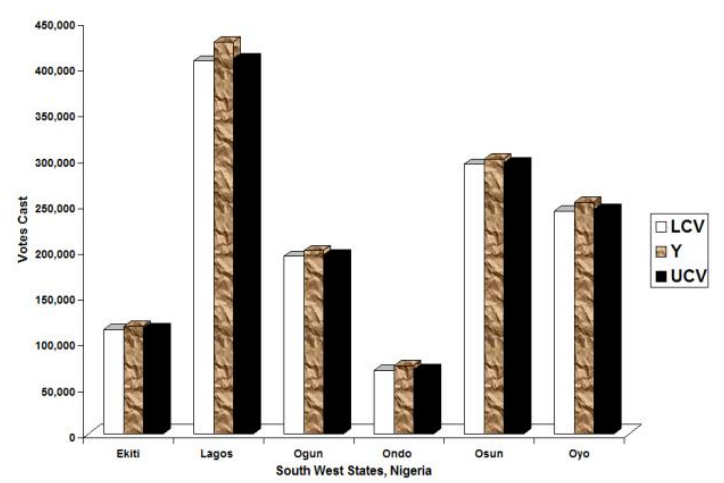

Figure 2: Electoral votes in favour of $A C N$ in 2011 presidential election

However, in 2015 presidential elections presented in Tables 3 and 4 shows that the reported votes cast in favour of APC and PDP compared to their expected votes, reflect negligible differences. Furthermore, all reported votes cast in favour of these political parties in the respective states are within the computed Bayesian interval bounds (LCV and UCV). These results are graphically represented in Figures 3 and 4. 


\section{Ogundeji and Onyeka-Ubaka: A Bayesian Approach for Validation of Election Results}

Table 1: Analysis of votes cast for PDP in 2011 presidential election and computed bayesian credible interval bounds

\begin{tabular}{ccccccccccc}
\hline State & $\mathbf{n}$ & $\mathbf{y}$ & $\mathbf{P}_{\mathbf{0}}$ & $\mathbf{P}_{\mathrm{EB}}$ & $\mathbf{E}(\mathbf{y})$ & $\mathbf{L C L}$ & $\mathbf{U C L}$ & $\mathbf{L C V}$ & $\mathbf{U C V}$ & $\mathbf{y}-\mathbf{E}(\mathbf{y})$ \\
\hline Ekiti & 261,858 & 135,009 & 0.51558 & 0.50559 & 132,392 & 0.50367 & 0.50750 & 131,890 & 132,893 & 2,617 \\
Lagos & $1,945,044$ & $1,281,688$ & 0.65895 & 0.64895 & $1,262,237$ & 0.64828 & 0.64962 & $1,260,941$ & $1,263,533$ & 19,451 \\
Ogun & 543,715 & 309,177 & 0.56864 & 0.55864 & 303,740 & 0.55732 & 0.55996 & 303,025 & 304,456 & 5,437 \\
Ondo & 486,837 & 387,376 & 0.79570 & 0.78569 & 382,505 & 0.78456 & 0.78683 & 381,954 & 383,056 & 4,871 \\
Osun & 512,714 & 188,409 & 0.36747 & 0.35748 & 183,285 & 0.35616 & 0.35880 & 182,608 & 183,962 & 5,124 \\
Oyo & 863,544 & 484,758 & 0.56136 & 0.55136 & 476,123 & 0.55031 & 0.55241 & 475,219 & 477,027 & 8,635 \\
\hline
\end{tabular}

$\mathrm{n}=$ Total number of electorates that voted, $\mathrm{y}=$ Total number of electorates in favour of a political party (Reported Vote Cast), Po $=$ Prior Probabilities, $\mathrm{PEB}=$ Posterior Probabilities, $\mathrm{E}(\mathrm{y})=$ Expected Votes, $\mathrm{LCL}=$ Lower Credible Limit, UCL $=$ Upper Credible Limit, LCV $=\mathrm{Lower}$ Credible Votes, UCV = Upper Credible Votes, $[\mathrm{y}-\mathrm{E}(\mathrm{y})]$ = Difference between Reported Votes and Expected Votes.

Table 2: Analysis of votes cast for ACN in 2011 presidential election and computed bayesian credible interval bounds

\begin{tabular}{ccccccccccc}
\hline State & $\mathbf{n}$ & $\mathbf{y}$ & $\mathbf{P}_{\mathbf{0}}$ & $\mathbf{P}_{\mathrm{EB}}$ & $\mathbf{E}(\mathbf{y})$ & $\mathbf{L C L}$ & $\mathbf{U C L}$ & $\mathbf{L C V}$ & $\mathbf{U C V}$ & $\mathbf{y}-\mathbf{E}(\mathbf{y})$ \\
\hline Ekiti & 261,858 & 116,981 & 0.44673 & 0.43673 & 114,361 & 0.43482 & 0.43863 & 113,862 & 114,859 & 2,620 \\
Lagos & $1,945,044$ & 427,203 & 0.21964 & 0.20964 & 407,754 & 0.20906 & 0.21022 & 406,622 & 408,885 & 19,449 \\
Ogun & 543,715 & 199,555 & 0.36702 & 0.35702 & 194,117 & 0.35574 & 0.35830 & 193,420 & 194,814 & 5,438 \\
Ondo & 486,837 & 74,253 & 0.15252 & 0.14252 & 69,386 & 0.14151 & 0.14353 & 68,895 & 69,878 & 4,867 \\
Osun & 512,714 & 299,711 & 0.58456 & 0.57455 & 294,580 & 0.57320 & 0.57590 & 293,889 & 295,272 & 5,131 \\
Oyo & 863,544 & 252,240 & 0.29210 & 0.28210 & 243,605 & 0.28114 & 0.28306 & 242,776 & 244,433 & 8,635 \\
\hline
\end{tabular}

Table 3: Analysis of votes cast for APC in 2015 presidential election and computed bayesian credible interval bounds

\begin{tabular}{ccccccccccc}
\hline State & $\mathbf{n}$ & $\mathbf{y}$ & $\mathbf{P}_{\mathbf{0}}$ & $\mathbf{P}_{\mathrm{EB}}$ & $\mathbf{E}(\mathbf{y})$ & $\mathbf{L C L}$ & $\mathbf{U C L}$ & $\mathbf{L C V}$ & $\mathbf{U C V}$ & $\mathbf{y}-\mathbf{E}(\mathbf{y})$ \\
\hline Ekiti & 300,691 & 120,331 & 0.40018 & 0.40023 & 120,347 & 0.39848 & 0.40198 & 119,820 & 120,873 & -16 \\
Lagos & $1,443,686$ & 792,460 & 0.54891 & 0.54891 & 792,461 & 0.54810 & 0.54973 & 791,289 & 793,633 & -1 \\
Ogun & 533,173 & 308,290 & 0.57822 & 0.57821 & 308,288 & 0.57689 & 0.57954 & 307,581 & 308,995 & 2 \\
Ondo & 561,056 & 299,889 & 0.53451 & 0.53451 & 299,891 & 0.53321 & 0.53582 & 299,159 & 300,624 & -2 \\
Osun & 642,615 & 383,603 & 0.59694 & 0.59693 & 383,599 & 0.59574 & 0.59813 & 382,828 & 384,370 & 4 \\
Oyo & 881,352 & 528,620 & 0.59978 & 0.59978 & 528,616 & 0.59876 & 0.60080 & 527,714 & 529,517 & 4 \\
\hline
\end{tabular}


Nigerian Journal of Basic and Applied Science (December, 2019), 27(2): 22-31

Table 4: Analysis of votes cast for PDP in 2015 presidential election and computed bayesian credible interval bounds

\begin{tabular}{ccccccccccc}
\hline State & $\mathbf{n}$ & $\mathbf{y}$ & $\mathbf{P}_{\mathbf{0}}$ & $\mathbf{P}_{\mathrm{EB}}$ & $\mathbf{E}(\mathbf{y})$ & $\mathbf{L C L}$ & $\mathbf{U C L}$ & $\mathbf{L C V}$ & $\mathbf{U C V}$ & $\mathbf{y}-\mathbf{E}(\mathbf{y})$ \\
\hline Ekiti & 300,691 & 176,466 & 0.58687 & 0.58683 & 176,455 & 0.58507 & 0.58859 & 175,925 & 176,984 & 11 \\
Lagos & $1,443,686$ & 632,327 & 0.43799 & 0.43799 & 632,326 & 0.43718 & 0.43880 & 631,157 & 633,494 & 1 \\
Ogun & 533,173 & 207,950 & 0.39002 & 0.39003 & 207,952 & 0.38872 & 0.39134 & 207,254 & 208,650 & -2 \\
Ondo & 561,056 & 251,368 & 0.44803 & 0.44802 & 251,366 & 0.44672 & 0.44932 & 250,636 & 252,096 & 2 \\
Osun & 642,615 & 249,929 & 0.38892 & 0.38893 & 249,931 & 0.38774 & 0.39012 & 249,165 & 250,697 & -2 \\
Oyo & 881,352 & 303,376 & 0.34422 & 0.34422 & 303,381 & 0.34323 & 0.34521 & 302,507 & 304,255 & -5 \\
\hline
\end{tabular}

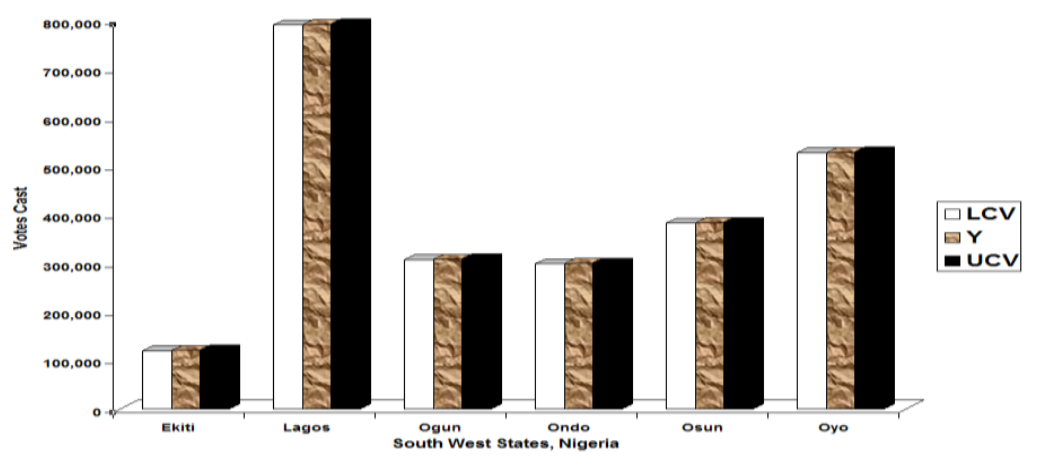

Figure 3: Electoral votes in favour of APC in 2015 presidential election

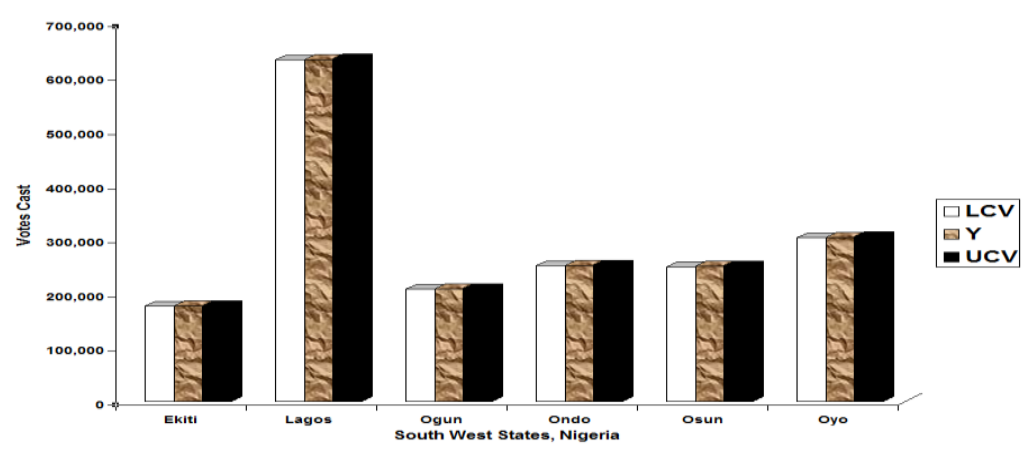

Figure 4: Electoral votes in favour of PDP in 2015 presidential election 


\section{Ogundeji and Onyeka-Ubaka: A Bayesian Approach for Validation of Election Results}

The results show that the presidential elections in 2015 in the respective states are credible and of minimal irregularities, given the reported votes cast. The reliability of an estomator measured by the effficiency of that estomator is based on minimum variance of the estimator amongst other unbiased estmators. For two unbiased estimators, the relative efficiency gives the more reliable estimator indicated by smaller variances. To check for the reliability of Bayesian approach in contrast to frequentist approach, the variances of the posterior estimates were computed and compared (Tables 5 and 6).

Table 5: Variances of posterior estimates and differences between frequentist and bayesian approaches for 2011 presidential elections.

\begin{tabular}{ccccccc}
\hline & \multicolumn{2}{c}{ PDP 2011 Election Results } & \multicolumn{2}{c}{ ACN 2011 Election Results } \\
State & Frequentist & Bayesian & Differences & Frequentist & Bayesian & Differences \\
\hline Ekiti & $9.53788 \mathrm{E}-07$ & $9.53735 \mathrm{E}-07$ & $5.30776 \mathrm{E}-11$ & $9.43878 \mathrm{E}-07$ & $9.4383 \mathrm{E}-07$ & $4.77145 \mathrm{E}-11$ \\
Lagos & $1.15542 \mathrm{E}-07$ & $1.15541 \mathrm{E}-07$ & $8.6568 \mathrm{E}-13$ & $8.81197 \mathrm{E}-08$ & $8.8119 \mathrm{E}-08$ & $5.9974 \mathrm{E}-13$ \\
Ogun & $4.51135 \mathrm{E}-07$ & $4.51123 \mathrm{E}-07$ & $1.20913 \mathrm{E}-11$ & $4.27276 \mathrm{E}-07$ & $4.2727 \mathrm{E}-07$ & $1.04028 \mathrm{E}-11$ \\
Ondo & $3.33921 \mathrm{E}-07$ & $3.33911 \mathrm{E}-07$ & $9.9953 \mathrm{E}-12$ & $2.65512 \mathrm{E}-07$ & $2.655 \mathrm{E}-07$ & $7.21957 \mathrm{E}-12$ \\
Osun & $4.53349 \mathrm{E}-07$ & $4.53336 \mathrm{E}-07$ & $1.28853 \mathrm{E}-11$ & $4.73658 \mathrm{E}-07$ & $4.7365 \mathrm{E}-07$ & $1.22293 \mathrm{E}-11$ \\
Oyo & $2.85145 \mathrm{E}-07$ & $2.8514 \mathrm{E}-07$ & $4.81197 \mathrm{E}-12$ & $2.39452 \mathrm{E}-07$ & $2.3945 \mathrm{E}-07$ & $3.6707 \mathrm{E}-12$ \\
\hline
\end{tabular}

Table 6: Variances of posterior estimates and differences between frequentist and Bayesian approaches for 2015 presidential elections.

\begin{tabular}{ccccccc}
\hline & \multicolumn{2}{c}{ ACN 2015 Election Results } & \multicolumn{2}{c}{ PDP 2015 Election Results } \\
State & Frequentist & Bayesian & Differences & Frequentist & Bayesian & Differences \\
\hline Ekiti & $7.98317 \mathrm{E}-07$ & $7.98049 \mathrm{E}-07$ & $2.68201 \mathrm{E}-10$ & $8.06345 \mathrm{E}-07$ & $8.0616 \mathrm{E}-07$ & $1.84522 \mathrm{E}-10$ \\
Lagos & $1.71511 \mathrm{E}-07$ & $1.71499 \mathrm{E}-07$ & $1.20044 \mathrm{E}-11$ & $1.70505 \mathrm{E}-07$ & $1.705 \mathrm{E}-07$ & $8.12813 \mathrm{E}-12$ \\
Ogun & $4.57417 \mathrm{E}-07$ & $4.57331 \mathrm{E}-07$ & $8.6679 \mathrm{E}-11$ & $4.46208 \mathrm{E}-07$ & $4.4615 \mathrm{E}-07$ & $5.75918 \mathrm{E}-11$ \\
Ondo & $4.43465 \mathrm{E}-07$ & $4.43386 \mathrm{E}-07$ & $7.98596 \mathrm{E}-11$ & $4.40773 \mathrm{E}-07$ & $4.4072 \mathrm{E}-07$ & $5.40634 \mathrm{E}-11$ \\
Osun & $3.74413 \mathrm{E}-07$ & $3.74355 \mathrm{E}-07$ & $5.88687 \mathrm{E}-11$ & $3.69837 \mathrm{E}-07$ & $3.698 \mathrm{E}-07$ & $3.9606 \mathrm{E}-11$ \\
Oyo & $2.72359 \mathrm{E}-07$ & $2.72328 \mathrm{E}-07$ & $3.12244 \mathrm{E}-11$ & $2.56122 \mathrm{E}-07$ & $2.561 \mathrm{E}-07$ & $1.99991 \mathrm{E}-11$ \\
\hline
\end{tabular}

The analysis of the differences between the variances of posterior estimates using both frequentist and Bayesian approaches shows that Bayesian approach is a better approach. This is justified by the fact that Bayesian estimators are more efficient based on the possession of smaller variances.

\section{DISCUSSION}

Many authors have worked on election processes and results and have considered issues of election forecasting, electoral behaviour, opinion polls and pre-election survey using different statistical inference (Lewis-Beck, 2005; Mann, 2005; Holbrook and DeSart 1999; Stegmuller, 2014). This study has presented a Bayesian statistical approach for analysis and validation of election results. The results of the analysis highlight the following: lower and upper credible limits for votes cast, expected votes cast, variances for the estimates etc. Noted diffences in the actual votes cast and expected votes cast were significant especially in lagos state for 2011 presidential election, possible due to electoral fraud or logistics probems on the part of INEC (See Table 1 and 2). 
By comparing results from both frequentist and Bayesian inferences, the results in this article extended the work of Iwok and Apkan, (2016) on 2015 Nigeria presidential election using Bayesian approach only. The results also focused on election results both in 2011 and 2015 South Western Nigeria.

In this research, results were obtained for both frequentists and Bayesian statistical inferences and compared. Also the results obtained in this research compared favorably with the work of Adewara and Ogundeji (2017) where data sequenced over some periods using similar methodology and approaches to determine the proportion of orthopaedic cases.

\section{CONCLUSION}

Empirical Bayes have been employed in many situations where information from several but similar sources can be combined. In particular, this work has shown that Bayesian methods for estimating proportion are most appropriate in cases of validation of election results. In contrast to frequentist approach, applied Bayesian methodology exhibited smaller variances which is an indication that Bayesian approach is more efficient (i.e. simply more reliable). Thus, results show that the EB estimators are better estimators on the basis of efficiency and consistency properties of good estimators.

This study has established statistically the validity of the reported votes cast in favour of the top-two political parties from the South West zone of Nigeria in 2015 presidential elections. Further studies can be conducted on expanded data beyond the South West zone election results to cover the remaining geo-political zones in Nigeria. The outcome of such analysis will further establish the credibility or otherwise of the 2011 and 2015 Nigeria presidential elections.

\section{REFERENCES}

Adewara A. J. and Ogundeji, R. K. (2017). Proportional estimation of sequential bayesian using orthopaedic surgery data in Nigeria. Nigerian Journal of Scientific Research, 16(64): 435 - 440.

Brown, L. B. and Chappell, H. W. Jr. (1999). Forecasting presidential elections using history and polls. International Journal of Forecasting, 15: 127-135.

Carlin, B. P. and Louis, T. A. (2000), Empirical bayes: past, present and future. Journal of the American Statistical Association, 95(452): 1286-1289.

Christensen, W. F. and Florence, L. W. (2008). Predicting presidential and other multistage election outcomes using state level pre-election polls, special section: statistics for democratic processes. Journal of American Statistical Association, 62(1): 1-10.

Gray, K., Hampton, B., Silvetis-Falls, T., McConnell, A. and Bausell, C. (2015). Comparison of bayesian credible intervals to frequentist confidence intervals. Journal of Modern Applied Statistical Methods, 14(1): 43-52.

Hillygus, S. (2011). The evolution of election polling in the united states. Public Opinion Quarterly, 75(5): 962-981.

Holbrook, T. and DeSart, J. (1999). In American states. International Journal of Forecasting, 15:137-142.

Iwok, I. A. and Akpan, N. P. (2016). Bayesian approach to electoral processes. International Journal of Statistics and Applications. 6(5): 309-313.

Kenneth, E. H. (2014). Bayesian concept of election matters. a case study of Ghana's gubernatorial election. International Journal of Political Science, 3(8):72 - 81 .

Lee, P. (2004), Bayesian statistics an Introduction, Hodder Arnold, New York.

Lewis-Beck, M. S. (2005). Election forecasting: principle and practice. British Journal of Politics and International Relations, 7(2): 145-164.

Mann, C. B. (2005). Do advance letters improve pre-election forecast accuracy? The 


\section{Ogundeji and Onyeka-Ubaka: A Bayesian Approach for Validation of Election Results}

Public Opinion Quarterly, 69(4): 561571.

Okafor, R. (1999). Using an empirical bayes model to estimate currency exchange rate. Journal of Applied Statistics, 26(8): 973-983.

Okafor, R. O., Opara, A. I., Ogundeji, R. K., Mbata, U. A. and Olalude, G. A. (2010), Empirical bayes model for inference on vehicular traffic density at the main campus of university of Lagos, Nigeria, International Journal of Statistics and Systems, 5(1): 53-62.

Ogundeji, R. K. and Okafor, R. O. (2010). Empirical bayes approach to estimate mean CGPA of university graduates. International Journal of Applied Mathematics \& Statistics, 17(10): 77-89.

Rigdon, S. E., Jacobson, S. H., Cho, W. K. T., Sewell, E. C. and Rigdon, C. J. (2009). A bayesian prediction model for the U.S. presidential election. American Politics Research, 37:700-724.

Rosenstone, S. J. (1986). Forecasting presidential elections. International Journal of Forecasting, 2(2):248 - 249.

Stegmuller, D. (2014). Bayesian Hierarchical Age- Period-Cohort models with timestructure effects: an application to religious voting in the US, $1972-2008$. www.researchgate.net. Published in Electoral Studies, 33: 52-62.

Theobald D. L. and Wuttke D. S. (2006). Empirical bayes hierarchical models for regularizing maximum likelihood estimation in the matrix gaussian procrustes problem. The National Academy of Sciences of the USA, 103(49): 18521-18527. 